\title{
Nephrogenic Diabetes Insipidus - A Rare Report of Two Affected Sibling
}

\author{
RUMANA RIAAZ, MAHBUB MUTANABBI, KOHINOOR JAHAN SHAMALY, C.A. KAWSER.
}

\begin{abstract}
Nephrogenic Diabetes Insipidus (NDI) is a type of Diabetes Insipidus (DI) where distal nephrons are unresponsive to antidiuretic hormone resulting in polyuria and polydipsia. NDI can be congenital or acquired. There are very few cases of congenital NDI, more in sibs. Here we report two sibs affected with congenital NDI. Both of them presented with polyuria, polydipsia and failure to thrive since early infancy. In both cases, water deprivation tests and urine osmolality were done before and after DDAVP that suggested NDI and the acquired causes has been excluded. Both of them were treated with oral Hydrochlorothiazide and improved.
\end{abstract}

Key words: Nephrogenic Diabetes Insipidus, congenital, antidiuretic hormone.

\section{Introduction}

Diabetes Insipidus (DI) is a condition characterized by the body's inability to conserve water or to concentrate the urine, leading to polydipsia and polyuria. While central DI is caused by the failure to release enough vasopressin (antidiuretic hormone), Nephrogenic DI (NDI) is due to insensitivity of the distal nephron to the antidiuretic effect of $\mathrm{ADH} .{ }^{1} \mathrm{NDI}$ can be divided in two forms, acquired and congenital. Acquired $\mathrm{NDI}$ is the most common form and can be seen in several pathological conditions such as renal hypoplasia, interstitial nephritis, chronic renal failure, obstructive uropathy, sickle cell disease, hypokalemia, hypercalcemia. NDI may be genetically transmitted as an X-linked, autosomal recessive or autosomal dominant trait.X-linked NDI is a rare disease with an estimated prevalence of approximately four per 1 million males. ${ }^{2}$ Here we reported two sibs affected in a family with NDI. Occasional cases of NDI arefound but two sibsis rarely seen. That is why we are reporting these cases.

1. Resident, Phase-B, Department of Paediatrics, Bangabandhu Sheikh Mujib Medical University, Dhaka,

2. Associate Professor, Department of Paediatrics, Bangabandhu Sheikh Mujib Medical University, Dhaka,

3. Resident, Phase-B, Department of Paediatrics, Bangabandhu Sheikh Mujib Medical University, Dhaka,

4. Professor, Department of Paediatrics, Bangabandhu Sheikh Mujib Medical University, Dhaka,

Correspondence: Dr. Rumana Riaaz, Resident, Phase-B, Department of Paediatrics, Bangabandhu Sheikh Mujib Medical University, Dhaka, Mob: 01716430660, E-mail: riaazrumana@ gmail.com

\section{Reports}

\section{Case 1}

The first case was admitted at the age of 23 months with the complaints of polydipsia, polyuria since 6 months of age. He was the $4^{\text {th }}$ issue of nonconsanguineous parents. He had low grade irregular fever for same duration \& history of weight loss for last 1 year. He drinks around 12-15 glasses of water daily and voided 15-20 times in a day and 3-4 times at night. He had delay in motor development. His neck control was achieved at 6 months and walking at the age of 20 months. He had no history of constipation, dehydration, vomiting or any features suggestive of Diabetes Mellitus, Central Nervous System infection, trauma andtumor. He has no history of drug intake.

On examination, he was active, co-operative, not pale, afebrile, some dehydration was present, pulse $120 \mathrm{~b} /$ min, BP was $80 / 50 \mathrm{~mm} \mathrm{Hg}$, Respiratory Rate-24 br/ min and bed side urine for albumin was nil. He was moderately wasted and stunted (Weight: $10 \mathrm{~kg}$ (WAZ -1.95), Height: $77 \mathrm{~cm}$ (HAZ -2.82), OFC: $44 \mathrm{~cm}$ (below $3^{\text {rd }}$ centile). Systemic examinations were unremarkable.

Laboratory investigations showed a low specific gravity of urine (1000), serum electrolyte showed- Na-141 meq/l, K-3.2 meq/l, cl-111 meq/l, TCO2-28 meq/L. Complete blood count was normal. He was euglycemic (5.7 mg/dl). His serum calcium was $2.61 \mathrm{mmol} / \mathrm{L}$ ( normal- 2.2 to $2.7 \mathrm{mmol} / \mathrm{L}$ ), inorganic phosphate was $1.72 \mathrm{mmol} / \mathrm{L}$ (normal-1.12 TO $1.45 \mathrm{mmol} / \mathrm{L}$ ) and 24 hours urinary calcium was $0.01 \mathrm{mg} / \mathrm{L}, \mathrm{X}$-ray of KUB 
region showed normal. Serum creatinine was normal $(0.3 \mathrm{mg} / \mathrm{dl})$. His urine osmolality was $71 \mathrm{mosm} / \mathrm{L}$ and serum osmolality was $287 \mathrm{mosml} / \mathrm{L}$. After water deprivation test serum osmolality was raised (301 mosm/L) but urine osmolality was still $70 \mathrm{mosm} / \mathrm{L}$. A subsequent dose of DDAVP 10 microgram given intranasally failed to increase the urine osmolality (62 mosm/L). CT scan of brain was not done.

He was prescribed with tab. Hydrochlorothiazide 25 mg once daily. Total urine volume was decreased by approximately $50 \%$ after administration of drugs, reaching to 10-12 times and polydipsia also decreased and he is now thriving well.

\section{Case 2}

Elder brother of first case was admitted in BSMMU at the age of 13 th months, $3^{\text {rd }}$ issue of nonconsanguineous parents, fully immunized, presented similarly with polyuria, polydipsia and growth failure for six months. He used to take 2-3 $L$ of water and voided 20-25 times. He had history of recurrent vomiting with low grade intermittent fever without any localizing sign. No history of cranial irradiation, head trauma, head surgery or taking any offending drug. The child had developmental delay. At the age of $13^{\text {th }}$ month he was not able to walk even with support, only could sit but couldn't stand. On examination, he was well alert, joyful, afebrile, mildly dehydrated, normotensive with pulse rate $112 \mathrm{~b} / \mathrm{min}$, respiratory rate $28 \mathrm{br} / \mathrm{min}$ and had brachicephaly. His weight was $7.1 \mathrm{~kg}$ (WAZ $-3.88 \mathrm{SD}$ ), length was $73 \mathrm{~cm}$ (on $10^{\text {th }}$ centile). Other physical examinations were within normal limit.

Investigations showed a low specific gravity (1005) with no proteinuria or reducing substance in urine, normal serum electrolyte ( $\mathrm{Na}-137 \mathrm{mmol} / \mathrm{l}-3.57 \mathrm{mmol} /$ $\mathrm{I}, \mathrm{Cl}-103 \mathrm{mmol} / \mathrm{l})$. His hemoglobin was $10.8 \mathrm{gm} / \mathrm{dl}$, total WBC count $12000 / \mathrm{cmm}$, platelet count was $3,71,000 / \mathrm{cmm}$. Serum creatinine was $0.34 \mathrm{mg} / \mathrm{dl}$, urinary total calcium was $0.46 \mathrm{mgl} / \mathrm{L}$. His urine osmolality was low $(60 \mathrm{mosm} / \mathrm{kg}$ ) and serum osmolality was $271 \mathrm{mosm} / \mathrm{kg}$. Water deprivation test was performed. Urine osmolality was not significantly increased even at the end of test $(72 \mathrm{mosmL})$ which was initially $74 \mathrm{mosm} / \mathrm{L}$. Failure to increase urinary osmolality one hour after vasopressin (DDAVP) nasal spray suggested nephrogenic DI (urine osmolality103 mosm/l, serum osmolality 275 mosm/L). CT scan revealed calcification of basal ganglia. The child was treated with tab. Hydrochlorothiazide $(3 \mathrm{mg} / \mathrm{kg}$ ) and the child responded very well, polyuria, polydipsia was subsided, was gaining weight. But accidently he died from drowning at the age of 30 months.

\section{Discussion}

Nephrogenic diabetes insipidus is characterized by decreased responsiveness of distal tubule and collecting duct to antidiuretic hormone (ADH). Resistant to action of ADH as in NDI is associated with increased loss of free water, polyuria,low urine osmolality and increased serum osmolality. ${ }^{1,3}$ Three different inheritance patterns have been recognized.Congenital NDI is a rare disorder secondary to either mutation in the AQP2 gene that codes for the vasopressin-depended water channel aquaporin. ${ }^{2}$ Mutations in the gene located on X q28 coding for the V2 receptor of vasopressin (AVPR2 gene) are responsible for the $X$-linked mode of inheritance, while mutation of AQP2 gene are found in the autosomal recessive and dominant traits of disease. About $90 \%$ of symptomatic patients are male. ${ }^{2}$

In most cases, approximately $90 \%$ are transmitted as an X-link recessive trait in the families. Female carriers were clinically unaffected, transmitting the disease to their sons who display the complete clinical picture. In 1998, the major NDI locus was mapped in the distal region of long arm of the $X$ chromosome $(X$ q28) and in 1992 the gene in VR2 was shown to underline X-linked NDI. ${ }^{4,5}$

In a minority of families, approximately $10 \%$ of transmission and phenotypic characteristics of NDI are not compatible with an X- linked trait. In these families, females display a complete clinical picture of NDI and polymorphic DNA marker from the Xq28 region, a family pedigree has suggested the existence of both autosomal recessive and dominant forms of NDI. In the recent years, it has been demonstrated that both autosomal forms are caused by amutation of an AVP sensitive AQP2 water channel. ${ }^{6}$

In our patients, genetic analysis of AVPR2 sequence were not possible to perform but there was no family history of such type of illness in maternal uncle or grandparents. The existence of the phenotype carrier of the AVPR2 mutation varying from no symptom to complete manifestation of the disorder could be attributed to a skewed X inactivation. ${ }^{7}$

The polyuria and polydipsia associated with genetic NDI usually presents within the first several weeks of life but may only be apparent after weaning. Our two 
cases presented with the feature of polyuria and polydipsia after weaning. Many infants initially present with fever, vomiting, dehydration and failure to thrive. In both of our cases there were intermittent fever, vomiting and failure to thrive. Acquired causes were excluded by doing serum calcium, serum potassium, serum creatinine, X-ray KUB region. Drug history that may be responsible for NDI like lithium, demeclocycline, foscarnet, clozapine, amphotericin, methicillin and Rifampicin were excluded (1). Our second case had intracranial calcification in basal ganglia in CT scan. Calcification in children with NDI have previously been described in basal ganglia, caudate nuclei and frontal, parietal and occipital lobes. Episodes of recurrent hypernatremic dehydration can cause necrosis of endothelial cells and dystrophic calcification in the affected areas. , $^{8,10,11}$

Management of children with NDI requires education of parents regarding the importance of liberal fluid intake and avoidance of dehydration. Lowering of solute load to the kidneys help by decreasing free water loss. Combination of hydrochlorothiazide ( $2-3 \mathrm{mg} / \mathrm{kg} / \mathrm{day})$ and amiloride $(0.3 \mathrm{mg} / \mathrm{kg} /$ day $)$ has been used to decrease urine output in these patients as much as $30-40 \%{ }^{12}$ Both of our cases were treated with tab hydrochlorothiazide with a dose of $2.5 \mathrm{mg} / \mathrm{kg} /$ day in two divided doses. Hydrochlorothiazide increases sodium excretion, resulting in decrease in extracellular sodium content that leads to an increase in the proximal tubular reabsorption of sodium and water. ${ }^{13}$

Few days after starting treatment, there was significant decrease in polyuria and polydipsia and patients were discharged and advised to come for regular follow up.

\section{Conclusion}

In conclusion, we report here two cases of congenital NDI that was diagnosed by typical clinical history and water deprivation test. Urinary volume can be reduced by medication. This study reports the clinical and laboratory characterization of NDI. Though genetic analysis was not possible to do in our cases but it is important for understanding the genetic basis of the disease and genetic counseling .

\section{Ethical Issue}

Written and signed informed consent from the guardian was taken for publishing this case report.

\section{References}

1. Bichet DG, Oksche A, Rosenthal W. Congenital Nephrogenic Diabetes Insipidus. Journal ofAmerican Society of Nephrology 1997;8 (12):1951-8.

2. Schliebe N, Strotman R, Busse K, Mitschke D, Biebermann H, Schomburg L, et al.V2 vasopressin receptor deficiency causes changes in expressions and function of renal and hypothalamic components involved in electrolyte and water homeostasis. Am J Physiol Renal Physiol. 2008; 295:1177-1190.

3. Robertson GL. Diabetes insipidus. Endo Clin North Am 1995;24:549-572.

4. Van den Ouwel and AM, Dreesen JC, Verdijk $\mathrm{M}$, et al. Mutations in the vasopressin type 2 receptor gene $\left(A \vee P R_{2}\right)$ associated with nephrogenic diabetes insipidus. Nat Genet 1992 Oct;2(2):99-102.

5. Pan Y, Metzenberg A, Das S, Jing B, Gitschier $J$. Mutations in the V2 vasopressin receptor gene are associated with $X$ linked Nephrogenic Diabetes Insipidus. Nat Genetics 1992 Oct;2(2):103-6.

6. Sato K, Fukuno H, Taniguchi T, Sawada S, Fukui $\mathrm{T}$, Kinoshita $\mathrm{M}$. A novel mutation in the vasopressin V2 receptor gene in a woman with congenital nephrogenic diabetes insipidus. Intern Med 1999 Oct;38(10):808-12.

7. Nomura $Y$, Onigata $K$, Nagashima $T$, et al. Detection of Skewed X-Inactivation on two female carriers of vasopressin type 2 receptor gene mutation. J Clin Endocrinal Metab 1997 Oct; 82(10): 3434-7.

8. Tohyama J, Inagakim M, Koeda T, Ohno K, Takeshita K. Intracranial calcification in siblings with nephrogenic diabetes insipidus. Neuroradiology 1993;35:553-555.

9. Schofer O, Beetz R, Kruse K, Rascher C, Schutz C, Bohl J. Nephrogenic diabetes insipidus and intracranial calcification. Arch Dis Child 1990;65:885-887.

10. Nozue T, Uemasu F, Sako A, Takagi Y. Intracranial calcification associated with nephrogenic diabetes insipidus. Pediatr Nephrol 1983;7:7476.

11. Ray M, Dixit A, Singhi P. Nephrogenic diabetes insipidus and intracranial calcification. Indian Pediatr 2002:39:197-202.

12. Kirchlenchner V, Koller DY, Seidl R, Waldhaauser F. Treatment of nephrogenic diabetes insipidus with hydrochlorothiazide and amiloride. Arch Dis Child 1999;80:548-552.

13. Bagga A, Kumar A, Bajaj G, Gupta A, Srivastava $\mathrm{RN}$. Intracranial calcification in nephrogenic diabetes insipidus. ClinPediatr Nephrol 1996; 35 : 34-36. 